\title{
Anti-Exceptionalism about Logic
}

\author{
Stephen Read \\ Arché Research Centre \\ University of St Andrews, Scotland \\ slr@st-and.ac.uk
}

\begin{abstract}
Anti-exceptionalism about logic is the doctrine that logic does not require its own epistemology, for its methods are continuous with those of science. Although most recently urged by Williamson, the idea goes back at least to Lakatos, who wanted to adapt Popper's falsificationism and extend it not only to mathematics but to logic as well. But one needs to be careful here to distinguish the empirical from the a posteriori. Lakatos coined the term 'quasiempirical' for the counterinstances to putative mathematical and logical theses. Mathematics and logic may both be a posteriori, but it does not follow that they are empirical. Indeed, as Williamson has demonstrated, what counts as empirical knowledge, and the role of experience in acquiring knowledge, are both unclear. Moreover, knowledge, even of necessary truths, is fallible. Nonetheless, logical consequence holds in virtue of the meaning of the logical terms, just as consequence in general holds in virtue of the meanings of the concepts involved; and so logic is both analytic and necessary. In this respect, it is exceptional. But its methodology and its epistemology are the same as those of mathematics and science in being fallibilist, and counterexamples to seemingly analytic truths are as likely as those in any scientific endeavour. What is needed is a new account of the evidential basis of knowledge, one which is, perhaps surprisingly, found in Aristotle.
\end{abstract}

Keywords: a posteriori, analytic, necessary; Aristotle, Lakatos, Williamson.

\section{Anti-Exceptionalism}

Tim Williamson has recently challenged the widely held belief that logic (and mathematics and philosophy) are different, exceptional, in being a priori, in contrast to the a posteriori and empirical position of science:

"Many contemporary philosophers who acknowledge metaphysics as continuous with the rest of science are still inclined to assign logic a more special status ... This book [Modal Logic as Metaphysics] is written in the contrary conviction that, just as metaphysics is much more like the rest of science than was once thought, so too is logic." 1

Put a little differently, he says that the a priori/a posteriori distinction is unhelpful, and doesn't serve to protect logic from scepticism. ${ }^{2}$ Admittedly, he says, philosophy, like mathematics, is an

\footnotetext{
${ }^{1}$ Williamson [2013b, p. x].

${ }^{2}$ See Williamson [2013c]. See also Williamson [2007, pp. 165 ff.] and [Williamson, 2013a, p. 3].
} 
armchair discipline, not to be conducted by observation or experiment. But these disciplines are not exceptions to the normal mechanism of theory-creation and theory-testing. Moreover, in both cases, experience is needed both to enable the judgment and as evidence for the judgment in such a way that neither can be reduced to zero, as the a priori/a posteriori distinction demands. ${ }^{3}$

Just like the other sciences, logical, philosophical and mathematical theories are established by an abductive method, compared and tested for strength, explanatory power, simplicity, elegance and consistency. In a side-swipe at certain trends in twentieth-century Anglo-American philosophy, Williamson claims that philosophical questions are not linguistic or conceptual questions - at least, no more than theoretical questions in the sciences - but are ordinary questions open to the same methodology as the rest. They may be challenged and confirmed only by thought-experiments in the armchair, but the method is the same. To establish some conjecture, $S$ say, we suppose not- $S$, infer that if $S$ did not obtain, neither would $S^{*}$, but not- $S^{*}$ is impossible, so we must concede $S$. Such claims are fallible, as any human claim is. We might be wrong. But whether it is the atomic number of lead, the circumference of the earth, the value of $\pi$, the law of excluded middle, the Barcan formula or the claim that knowledge is evidence, these claims are best understood as a posteriori, arrived at by abductive methods. ${ }^{4}$ In particular, logic is no exception.

Williamson also challenges the idea that logic, philosophy and mathematics are in any interesting sense analytic. Following Boghossian, he distinguishes metaphysical analyticity from epistemological analyticity. Metaphysical analyticity was the target of Quine's attack in 'Two Dogmas' [Quine, 1961a], that one could draw a clear line between matters of meaning and matters of fact. On this conception, some truths hold purely in virtue of meaning (conceptual truths), others in virtue of both meaning and fact. But that explains nothing, says Williamson. Dummett once claimed that meaning was transparent: that anyone who knew the meaning of two expressions whose meaning was the same must thereby know that their meaning was the same. ${ }^{5}$ This is the idea that Williamson [2000, §4.2] called "luminosity", and attacked as hostage to scepticism. Not all truths can be known - knowledge requires a margin for error. In fact, Kripke had already offered a counterexample to Dummett's transparency claim for meaning in his discussion of the puzzles of Pierre's: just as one can learn the names 'Londres' and 'London' (or even 'Paderewski' and 'Paderewski') without realising they name the same thing (or person), so too one can learn the words 'furze' and 'gorse' without realising they have the same meaning, indeed, even believing they are different. ${ }^{6}$ Not only can we have inconsistent beliefs (as Pierre believes that London is both pretty and not pretty), one can understand so-called analytic truths ('Furze is gorse' or 'Vixens are female foxes') without realising that they are true. Metaphysical analyticity is no guide to knowledge and the a priori.

The observation that 'necessary', ' a priori' and 'analytic' are not co-extensive, let alone synonymous, though most effectively made by Kripke, was voiced before him, e.g., in Sloman [1965-66]. Sloman bewailed the fact that too many writers treated the terms interchangeably, and so he sought both to clarify their meaning, and to point out their differences - which identifications and inclusions were problematic, and which even, perhaps, failed to hold. Interestingly, he characterised a statement as 'analytic' if the truth-value of the proposition it expressed could be discovered in an a priori manner from its logical construction along with the defining relation between its non-

\footnotetext{
${ }^{3} \mathrm{Cf}$. the distinction between concept-empiricism and judgment-empiricism, which tried to clarify the debate between rationalists and empiricists. See, e.g., Sellars [1989, Lecture 4].

${ }^{4}$ See Williamson [2013b, p.426].

${ }^{5}$ Dummett [1978a] in [1978b, p. 131]. See Williamson [2007, p. 67 n. 19], [2000, p. 96].

${ }^{6}$ Kripke [1979, p. 134], reprinted in Kripke [2011, p. 158].
} 
logical words, synthetic if not (p. 14). This is the concept which Boghossian [1997, p. 334] termed "epistemic analyticity", in contrast to metaphysical analyticity: in the latter sense, an analytic statement "owes its truth-value completely to its meaning and not at all to "the facts"; in the former, it is analytic if "mere grasp of [its] meaning [by someone] suffice[s] for [their] being justified in holding [it] true". As Sloman points out, if some true statements cannot be known, they are neither a priori nor empirical; similarly, they will be neither analytic nor synthetic - but nonetheless, might be necessary. Williamson's example [2013a, p. 2] is Cantor's Continuum Hypothesis: either it or its negation is a second-order logical truth, so metaphysically analytic but possibly beyond our ability to discover it. ${ }^{7}$ Thus both Boghossian [1997, p. 335] and Williamson [2007, p. $53]$ dismiss metaphysical analyticity as an idle and pointless notion.

Interestingly, Sloman does not use the term 'a posteriori', but his contrast between 'a priori' and 'empirical' suggests he follows the tradition since Kant in restricting the a posteriori to the empirical:

"It has been customary to say, even of much knowledge that is derived from empirical sources, that we have it or are capable of having it a priori ... In what follows ... we shall understand by a priori knowledge, not knowledge independent of this or that experience, but knowledge absolutely independent of all experience. Opposed to it is empirical knowledge, which is knowledge possible only a posteriori, that is, through experience." [Kant, 1963, p. 43]

But this is a departure from its original coining in the middle ages to mark a distinction first introduced by Aristotle, and an unnecessary duplication. Not only does it restrict the a priori, it identifies the a posteriori with the empirical. Anti-exceptionalism is the claim that, in the original sense of the term, an a posteriori methodology goes wider than what is discovered by sense experience. I will argue that Williamson is right to seek a more useful notion than what is currently captured by 'a posteriori', and will urge a return to the sense given to the term by the medievals. But I will also argue that Williamson is mistaken in his attack on analyticity. Logic is indeed, in the medieval sense, a posteriori; but it is also (epistemically) analytic: our understanding of the logical terms does justify us in making logical claims - though those claims can be mistaken, which is how the verdict of experience can lead us, a posteriori, to revise and develop our logical understanding.

\section{The A Posteriori}

The terms 'a priori' and 'a posteriori' were introduced by the medievals to capture Aristotle's distinction in his Posterior Analytics between demonstration why something obtains and demonstration simply that it obtains, the former explaining the effect by reference to its cause, the latter inferring the existence of the cause from the appearance of its effect. William of Ockham described the contrast in his Summa Logicae, written in the early 1320s:

\footnotetext{
${ }^{7}$ However, Sloman [1965-66, p. 14] claims that all logically true and logically false propositions are analytic and that every analytic proposition is a priori. This is so only because he characterizes logical truth and falsehood epistemically too: "if it is possible to discover the truth-value of a proposition expressed by a sentence simply by investigating ... the meanings of the logical constants employed ... then the proposition is said to be logically true." (p. 13)
}

Australasian Journal of Logic (16:7) 2019, Article no. 6 
"Demonstration is a syllogism leading to knowledge, that is, a certain and evident cognition ... and is of two kinds ... One is a demonstration whose premises are without qualification prior to the conclusion, and this is called demonstration a priori or why (propter quid). The other is demonstration whose premises are not without qualification prior to the conclusion, although they are better known to their proponent, whereby knowledge is gained of the conclusion, and this is called demonstration that (quia) or a posteriori." 8

The terminology was used by Albert the Great in his commentary on Aristotle's Posterior Analytics, written between 1245 and 1260:

"Let $A$ be the hewing of the stones, $C$ the erection of the walls (or some other middle) and $D$ the house. Then by syllogizing the earlier from the later (a posteriori), it follows that $A$ was done, because $C$ was done ... If a house was made (which is last to be produced) it follows that it is necessary that there are hewn stones ... It follows a posteriori that if there is a foundation of a house, it is necessary that there are hewn stones ... because hewn stones are a cause without which there is no foundation." ${ }^{9}$

Thus one can infer the cause from its effect, that is, a posteriori. The cause (the cutting of the stones) is an insufficient but necessary part of an unnecessary but sufficient condition of the effect (the house), what Mackie [1965] called an INUS condition. One could build a house a different way (e.g., from wood), but if one builds it from stones, the stones are necessary but not sufficient, for one also needs, e.g., a roof and a builder.

Aristotle's point was that demonstration is not always deduction from first principles, but can also be abductive, from observation to the best explanation. Douven [2011, Supplement: Peirce on Abduction] writes:

"The term 'abduction' was coined by Charles Sanders Peirce in his work on the logic of science ... Yet it is clear that, as Peirce understood the term, 'abduction' did not quite mean what it is currently taken to mean ... According to Peirce (Collected Papers 5.189), abduction belongs to logic because it can be given a schematic characterization, to wit, the following:

The surprising fact, $C$, is observed

But if $A$ were true, $C$ would be a matter of course

Hence, there is reason to suspect that $A$ is true."

That is exactly how Aristotle characterises demonstration from the fact a posteriori.

\footnotetext{
${ }^{8}$ [Ockham, 1974, III-2 17, pp. 532-3]: “[D] emonstratio est syllogismus faciens scire, accipiendo 'scire' pro notitia evidenti et certa ... et talis syllogismus sit multiplex ... [Q]uaedam est demonstratio cuius praemissae sunt simpliciter priores conclusione, et illa vocatur demonstratio a priori sive propter quid. Quaedam est demonstratio cuius praemissae non sunt simpliciter priores conclusione, sunt tamen notiores sic syllogizanti, per quas devenit sic syllogizans in notitiam conclusionis, et talis demonstratio vocatur demonstratio quia sive a posteriori." An alternative translation can be found at Ockham [2007, p. 175].

${ }^{9}$ Albert the Great [1651, II iii 6, pp. 639-41]: Sit a. decisio lapidum. c. parietum erectio, vel aliud medium, d. autem domus: tunc enim á posteriori syllogizando prius, sequitur, quod a. factum est, quoniam c. factum est ... si facta est domus (quae generatione ultima est) sequitur, quod necesse est decisos lapides esse ... sequitur á posteriori si fundamentum domus est, necesse est lapides decisos esse . . quia lapides decisi sunt causa sine qua non est fundamentum. For the date, and further discussion, see Longeway [2009, §4].
} 
Aristotle had given two examples to illustrate his distinction, both from astronomy. We can show that the planets are nearer than the stars because they do not twinkle. But their not twinkling is not an explanation of their being near. Rather, there being near is why they do not twinkle. So the cause (nearness) explains the effect (not twinkling), while their not twinkling shows that they are near. As Aristotle [1975, I 13] puts it, their not twinkling is the fact, their being near is the reason why.

Similarly, one can prove that the moon is a sphere by observing the way it waxes and wanes, but that does not explain why it is a sphere. Rather, its sphericity explains why it waxes and wanes as it does. Ockham adapts the example somewhat: one who infers that the moon is eclipsed from knowledge that the earth lies between it and the sun knows the reaon why it is eclipsed: "he would have a demonstration a priori, for the premises give the reason (causa) why the conclusion holds." But another might see the moon eclipsed and conclude that the earth must lie between the sun and the moon: "he makes a demonstration a posteriori. He knows that the earth is interposed, but does not know why it is interposed, and so he knows that it is so, but does not know why it is so." 10

Writing nearly a hundred years after Albert, John Buridan considered "Whether it is necessary that the premises [of a demonstration] are better known than the conclusion" and responded:

"From what has been said I conclude that the premises in a demonstration must be thought more true and more necessary than the conclusion, and that the truth and necessity of the premises must be thought, if not in fact, the cause of the truth or necessity of the conclusion. But in demonstration that and a posteriori this may not be so, rather the reverse." 11

Williamson's claim is that the abductive method is as true of logic, philosophy and mathematics as it is of the empirical sciences. The same point was famously made by Imre Lakatos, at least about mathematics, and arguably also about logic. He introduced the term 'quasi-empirical' to capture the fact that mathematics, in its actual practice, did not consist simply in deriving theorems from axioms and first principles (what he dubbed the "Euclidean model") but had to argue for those first principles, and indeed, motivate the very concepts involved, by a dialectical process of proof coming up against refutation, daring speculation challenged by dramatic counterexamples and criticism. At first, he characterised the quasi-empirical as the upwards retransmission of falsity from heuristic falsifiers (whether empirical or non-empirical in the traditional sense). In his later writings, however, he recognised that not only did Popper's method of conjecture and refutations (which initially inspired Lakatos' own conception of proof and refutation) need revision and sophistication (since, as Duhem had observed, no theory is refuted and abandoned on account of a single falsifying instance, as there are always "auxiliary hypotheses" onto which any challenge can be deflected), but there is also an upward transmission of truth, whether we call it "inductive"

\footnotetext{
${ }^{10}[$ Ockham, 1974, III-2 17, p. 533] : [T]alis habet demonstrationem a priori et propter quid, quia praemissae exprimunt causam propter quam sic est a parte rei sicut significatur esse per conclusionem ... [T]alis facit demonstrationem a posteriori; et scit quod terra interponitur, tamen nescit quare interponitur, et ita scit quia ita est, sed nescit propter quid ita est."

${ }^{11}$ Buridan [n.d., Questions on the Posterior Analytics]: Q 13 Utrum necesse sit magis scire praemissas quam conclusionem ... Et ex istis dictis finaliter concludo quod praemissae in demonstratione sunt magis verae et magis necessariae obiective quam conclusio, et quod veritas et necessitas praemissarum est obiective, non formaliter, causa veritatis vel necessitatis conclusionis. Tamen in demonstratione quid et a posteriori non esset ita, immo e converso." On the sense of 'obiective' in medieval philosophy, see, e.g., Read [1977].
} 
or "abductive", from a theory's consequences to its axioms. ${ }^{12}$

The editors of Proofs and Refutations question Lakatos' suggestion that in rejecting the Euclidean infallibilist approach we may need "to give up the idea that our deductive, inferential intuition is infallible." [Lakatos, 1976, p. 138] They speculate that Lakatos would have revised this assertion if he had lived to prepare the paper for publication, on the grounds that Lakatos "came to have the highest regard for formal deductive logic ... First order logic has arrived at a characterisation of the validity of an inference which ... does make valid inference essentially infallible." This would appear to be a typical Euclidean retrenchment, of which Lakatos repeatedly complained. For example, in Lakatos [1978b, p. 31] he notes:

"one can never refute Euclideanism", for example, "Hilbertians [defending the Hilbert programme of "establish[ing] once and for all the certitude of mathematical methods" p. 30] claimed that classical analysis contains an absolutely true Euclidean kernel."

Similarly, in logic, first-order logic became the true logic, formal and extensional, excluding areas of contention such as higher-order logic, modal logic, intuitionistic logic and the like. This is precisely the authoritarian, deductivist move against which Lakatos railed. ${ }^{13}$ That the unpublished passage in Appendix 1 to Lakatos [1976] was not a momentary deviation can be seen by looking, for example, at Lakatos [1978b, p. 25], where he identifies Russell as "probably the first modern logician to claim that the evidence for mathematics and logic may be "inductive"' (my italics), referring with approval to Russell's 1918 observation that: ${ }^{14}$

"if we are to believe in the truth of pure mathematics, it cannot be solely because we believe in the truth of the set of premises. Some of the premises are much less obvious than some of their consequences, and are believed chiefly because of their consequences ... It is not the logically simplest propositions of the system that are the most obvious, or that provide the chief part of our reasons for believing in the system. With the empirical sciences this is evident ... Exactly the same thing happens in the pure realm of logic; the logically first principles of logic - at least some of them - are to be believed, not on their own account, but on account of their consequences." [Russell, 1956, p. $325]$

It may at first glance seem implausible to liken Lakatos' proposed quasi-empirical methodology to Aristotle's, usually seen as that of a classic deductivist in the mould of Euclid. But neither philosophy is as single-minded as the apparent opposition describes. Aristotle was a naturalist: he rejected the pure rationalism of Plato in favour of a scientific model, where knowledge can be drawn both a priori, from the "reason why" (that is, from knowledge of the essence or cause), and a posteriori, from the "fact" (that is, from the effects):

"For nothing prevents the non-explanatory one of the counterpredicated terms from sometimes being more familiar, so that the demonstration will occur through this. E.g., that the planets are near, through their not twinkling: let $C$ be the planets, $B$ not twinkling, $A$ being near. Thus it is true to say $B$ of $C$, for the planets do not

\footnotetext{
${ }^{12}$ See Lakatos [1978a, pp. 150, 164 ff.]. See also Williamson [2017, §3].

${ }^{13}$ See, e.g., Lakatos [1976, Appendix 2: 'The deductivist versus the heuristic approach', pp. 142-3].

${ }^{14}$ Williamson [2016, p. 271] also cites Russell to the same effect, but from Russell [1973, pp. 273-4], written in 1907: "we tend to believe the premises because we can see that their consequences are true, instead of believing the consequences because we know the premises to be true."
} 
twinkle. But also 〈to say $A$ of $B$; for what does not twinkle is near (let this be got through induction or through perception). So it is necessary that $A$ belongs to $C$, so that it has been demonstrated that the planets are near. Now this deduction is not of the reason why but of the fact; for it is not because they do not twinkle that they are near, but because they are near they do not twinkle." [Aristotle, 1975, I 13 78a28-38]

In a similar way, Lakatos was not a dogmatic Popperian, basing everything on falsification, and indeed fell out with Popper by suggesting not only that Popper should soften his anti-inductivist campaign but that he had actually done so. ${ }^{15}$ He argued that the inductive (or as we might now say, abductive) method was not a thin, deductivist, analytic principle, but a synthetic, metaphysical commitment to "the methodology of scientific research programmes ... better suited for approximating the truth in our actual universe than any other methodology." 16

\section{Modality}

Lakatos' characteristic method was to illustrate his iconoclastic accounts of the epistemology of mathematics by tracing significant disputes in its history. The most famous is his extended discussion of Euler's "Theorem" in Proofs and Refutations. But he also instanced the history of the notion of continuous function in his discussion of Cauchy's defence of the claim that the limit of any convergent series of continuous functions is itself continuous [Lakatos, 1976, Appendix 1]; and, taking a topic on the borderline between logic and mathematics, the revision of set theory in the early twentieth century to exclude the contradictions [Lakatos, 1978b]. To illustrate the a posterioristic nature of logic, I propose to review some of the history of modal logic, concentrating on Aristotle and the medievals. Modal logic has always been something of a Cinderella topic, never invited to the main (logical) event. Part of the reason is that, at least as far as the prevailing conception of logic was concerned, Aristotle did not produce a coherent account of the logic of modality, in contrast to his success with the assertoric syllogism. ${ }^{17}$ Rather, the modalities, even the alethic modalities, necessity, possibility, impossibility and contingency, were thought to lie outside the central notions of logic: predication, assertion, denial, universality, partiality, opposition and implication. This is surprising, for necessity and impossibility are central to the very concept of logical consequence: one proposition is a logical consequence of another if it is impossible for the one to hold and the other not, that is, if the premises (e.g. of a syllogism) obtain, then necessarily so does the conclusion. A syllogism, [Aristotle, 2009, I 1 24b19-20] writes, is "a discourse in which certain things being stated, something other than what is stated follows of necessity from their being so." (my italics) To express the modal notion of consequence was C.I. Lewis' aim in replacing Russell's extensional logic with his theory of strict implication.

Nonetheless, Quine happily accepted Barcan Marcus' observation that he believed that "modal logic was conceived in sin", namely, Russell's conflation of the conditional 'if ... then' with implication. ${ }^{18}$ Setting aside his reservations about analyticity, he says in Quine [1960, p. 195], one might identify the necessity of strict implication with the metalinguistic predicate 'analytic'. The second grade of modality ${ }_{19}^{19}$ predicating necessity of a statement, might also be plausibly construed as sim-

\footnotetext{
${ }^{15}$ See Musgrave and Pigden [2016, §3.6].

${ }^{16}$ Lakatos [1978a, p. 165 n. 2; see also p. 166 n. 3].

${ }^{17}$ But see Malink [2013].

${ }^{18}$ See Barcan Marcus [1961, p. 303], Quine [1961b, p. 323].

${ }^{19}$ See Quine [1966].
} 
ilarly metalinguistic, he adds. But the real sin is to endorse the third grade of modal involvement, attributing modally qualified predicates to an object, or worse, quantifying into modal contexts, as in the famous Barcan formula involving expressions of the form $(\forall x) \square A(x)$ or $(\exists x) \diamond A(x)$. Coupled to his rejection of higher-order logic (as practiced by Frege and Russell, for example) as "mathematics in sheep's clothing" [Quine, 1970, p. 66], and his dismissal of alternative logics such as intuitionistic or paraconsistent logic as "changing the subject" [Quine, 1970, p. 80], Quine identified logic with first-order predicate logic with identity. ${ }^{20}$ The retrenchment behind a protective belt typifies, as Priest [2006, pp. 101-4] observed, what Lakatos called a "degenerating research programme". ${ }^{21}$

In fact, Aristotle's account of modal logic was challenged in his own lifetime, by Theophrastus and Eudemus, both students and colleagues of his. Theophrastus was named by Aristotle as his successor as head of the Lyceum, and ran the Peripatetic school until his death in about 287 BCE at the age of 85; Eudemus famously edited Aristotle's 'Eudemian Ethics', but left Athens to form his own school when he was passed over in the succession. The most famous challenge to Aristotle's modal syllogistic concerned what is popularly known as the problem of the two Barbaras, though that is something of a misnomer, since it applies to all the first figure mixed modality apodeictic syllogisms. Aristotle had claimed in Prior Analytics I 9 that an apodeictic conclusion (one stating a necessity) can be inferred, in the first figure, where the middle term is subject of one and predicate of the other premise, from one apodeictic premise and one assertoric, provided the apodeictic premise was the major premise, that is, the one containing the predicate of the conclusion. In a mix of medieval and modern jargon, he asserted the validity of Barbara, Celarent, Darii and Ferio LXL, but denied all corresponding first-figure cases of XLL. To show the validity of Barbara and Celarent LXL, he argued:

"If it has been assumed that $A$ belongs (or does not belong) to $B$ of necessity while $B$ merely belongs to $C, \ldots A$ will (or will not) belong to $C$ of necessity. For since $A$ belongs (or does not belong) to every $B$ of necessity, and $C$ is one of the $B \mathrm{~s}$, it is evident that one or the other will hold of $C$ of necessity." (30a17-22)

But when the major premise is not necessary, the conclusion will not be necessary, he said:

"For example, if $A$ were motion, $B$ animal, $\ldots C$ man. For man is an animal of necessity, but animal does not move of necessity, nor does man. Similarly, if $A B$ [the major premise] were privative [i.e., negative] for the demonstration is the same." $(30 \mathrm{a} 29-33)$

Theophrastus and Eudemus countered Aristotle's proof of Barbara LXL with a refutation, indeed, one deceptively similar to Aristotle's refutation of Barbara XLL. Alexander of Aphrodisias [1999, p. 59: 124,8-11] writes:

"Eudemus and Theophrastus ... say that in all the combinations of a necessary and an unqualified [i.e. assertoric] premise which are put together syllogistically, the conclusion is unqualified." 22

\footnotetext{
${ }^{20}$ See, e.g., Hylton [2014, §2.4].

${ }^{21}$ See Musgrave and Pigden [2016, §2.2]. See also Priest [1987, p. 145].

${ }^{22}$ See also Mueller's discussion in Alexander of Aphrodisias [1999, pp. 13-18]; and the further texts in Theophrastus of Ephesus [1992, pp. 207-23]. In what follows, I will refer only to Theophrastus, as others have done, for the sake of brevity.
} 
He attributes an argument to them, one which Mueller [Alexander of Aphrodisias, 1999, p. 119] finds obscure and unconvincing:

"They ... prove this by argument. For if $B$ holds of all $C$ but not by necessity, it is contingent that $B$ sometime be disjoined [or separated] from $C$. But when $B$ has been disjoined from $C, A$ will also be disjoined from it. And if this is so, $A$ will not hold of $C$ by necessity." [1999, 124,18-20]

The major premise is that $A$ holds of $B$ of necessity. But that does not seem to warrant the inference that if some $C$ is not $B$ then it is not $A$. The argument appears to be a fallacy of denying the antecedent: to show that the conclusion is not necessary if the minor premise is only assertoric, and so does not state a necessity, it attempts to infer the non-necessity (that is, contingency) that some $C$ is not $A$ from the non-necessity that some $C$ is not $B$. But for this we seem to need the major premise that $B$ belongs to every $A$ of necessity, whereas the major premise is in fact that $A$ belongs to every $B$ of necessity.

However, the argument could be construed as arguing in accordance with Darii LQQ (not mentioned by Aristotle, according to Malink [2013, p. 325; see also his discussion on pp. 158ff.]), where Q denotes contingency. First, we need to recall that Aristotle appears to use the notion of possibility in two senses, sometimes distinguished as one-way versus two-way possibility:

"By 'being possible' and 'the possible' I mean that which while not being necessary, will not lead to anything impossible when it is assumed to belong. For the necessary is called possible in a different sense." 23

The latter (what is not impossible, compatible with necessity) is one-way possibility, the usual sense of 'possible' in English; the former, which excludes necessity as well as impossibility (twoway possibility) is usually referred to as contingency. He notes at Prior Analytics I 13, 32a29-35: "'possibly belonging to some' converts to 'possibly not belonging to some'," where the sense of 'possibly' must be contingency. Thus Qo (that is, any proposition of the form 'it is contingent that some $C$ is not $B$ ') is equivalent to Qi ('it is contingent that some $C$ is $B$ ') ${ }^{24}$ Darii LQQ would then be equivalent to a new syllogism (not a modalization of any valid assertoric form) LQQ-aoo in figure 1: $A$ belongs to every $B$ of necessity, it is contingent that some $C$ is not $B$, so it is contingent that some $C$ is not $A$. Consequently, the premises of Barbara LXL would be compatible with the LQ premises, ' $A$ belongs of all $B$ of necessity' and 'It is contingent that $B$ does not belong to some $C^{\prime}$, from which we could infer that it is contingent that $A$ does not belong to some $C$, a conclusion incompatible with Aristotle's conclusion that $A$ belongs to all $C$ of necessity. Thus Aristotle was wrong, it seems, to claim that Barbara LXL is valid.

Alexander continues:

"[Theophrastus and Eudemus] also prove that this is so using material terms ... For animal holds of every human by necessity; let human hold of all that moves; it is not true that animal holds of all that moves by necessity." [1999, 124,21-25]

(To be on the safe side, they give two more counterexamples: knowledge, literate, human; moving by legs, walks, human.) This reverses Aristotle's example: instead of noting that it is not necessary

\footnotetext{
${ }^{23}$ See Aristotle [2009, I 13, 32a18-21]. See also I 3, 25a36-b25 and Striker's discussion at p. 71.

${ }^{24}$ However, according to Ammonius, Theophrastus and Eudemus rejected such complementary conversion. See Striker's discussion in Aristotle [2009, p. 91], and Theophrastus of Ephesus [1992, pp. 201-3].
} 
that men and animals move, neither is it necessary, they claim, that what moves be a man or an animal. But that is puzzling, for if Aristotle thought his counterexample disproved Barbara (and Celarent) XLL, why did he not also think it disproved LXL too?

This puzzle is, of course, only one among many that have been pinpointed in Aristotle's modal system. But like many others, I think it lies at the heart of the general issue: clarifying the nature of modality, in particular, necessity, what Aristotle's interpretation of it is, and whether it is correct or, if not, whether it is actually muddled or even incoherent. Tracing the issue through the history of attempts to make sense of Aristotle has strong similarities to Lakatos' tracing of Euler's theorem, the latter leading to greater clarity about the nature and types of polyhedra, the former subjecting the concepts of necessity, possibility and contingency to proof-analysis.

There are broadly two types of response to the problem of the two Barbaras, which we might dub the "metaphysical" and the "logical" responses. The former is typified by the responses of, inter alia, Averroes, Kilwardby and some modern commentators, most recently Malink [2013]. Thom [2003, p. 84] wrote:

"I propose a third reading that takes into account Averroes' larger purpose ... by means of an analysis that incorporates metaphysical as well as logical elements."

At its heart lies a distinction between the per se and per accidens status of the constituent terms, as it does in Kilwardby too [Thom, 2003, p. 95]. Similarly, Malink's interpretation of Aristotle's account of necessity distinguishes sharply between substance and non-substance terms. The difference beween Aristotle's and Theophrastus' counterexamples is that the subject of Aristotle's assertoric proposition is a substance term, while in Theophrasus' example it is an accidental (i.e., non-substance) term. So although it may seem that Theophrastus' minor premise ('Every moving thing is a man') is contingent (i.e., accidental), since other things than men can move, nonetheless, if every moving thing is a man, none of them is contingently so. 'Man' is the essence of its subjects, and so nothing can be a man contingently.

This approach has the advantage that it offers to make Aristotle's account coherent, even if there may be occasional incidental slips. ${ }^{25}$ It also offers an answer to a puzzle voiced by Corcoran $[1974$, p. 99] that there seems to be an even simpler counterexample to Barbara LXL than Theophrastus'. Let the major and middle terms be the same, e.g., 'man'. Then every man is necessarily a man, every man is moving (let us suppose), but it is false that every man is necessarily moving. But the account it gives of necessity, and modality, may be of only historical interest, and not of other interest or import. The logical approach, in contrast, mostly attributes substantial misunderstanding to Aristotle (and others), but offers to provide insight of current interest and import into the nature of modality. The prevailing logical analysis of the problem rests on recognising the de re/de dicto distinction, tracing back to Albrecht Becker [1933] in modern times, but anticipated by Abelard, William Ockham and John Buridan in medieval times, among others. Describing the two Barbaras, Ockham [1974, III-1 31, p. 443] wrote:

"If it is said that the Philosopher [i.e., Aristotle] denies one and grants the other, so what is said here, that one is as valid as the other, is false; it must be said that the Philosopher is speaking of the necessity-proposition in the divided sense. Then it is patently clear that the major [premise] being of necessity and the minor [premise] assertoric a necessity-conclusion follows, whether the minor [premise] is unrestrictedly

\footnotetext{
${ }^{25}$ Thom distinguishes between substantial mistakes, incidental mistakes and inconsistencies in Aristotle in [Thom, 1996, p. 123].
} 
assertoric, or assertoric as-of-now. But the argument is not valid in this way if the major [premise] is assertoric, and for that reason he denies one mixed [syllogism] and grants the other." ${ }^{26}$

There are (at least) two distinctions in play here. One is that between propositions of necessity (that is, necessity-propositions) taken de re and taken de dicto. Although this terminology is medieval (one finds it in Bacon [2009, §393, p. 197], for example), it is usually subsumed, as here, under a broader distinction, between the compounded (or composite) sense and the divided sense. The fallacy of composition and division was discussed by Aristotle in Sophistical Refutations, ch. 20: for example, I may have seen a man being beaten with my eyes, but it is a fallacy of composition to infer that he was beaten with my eyes. In the case of the Barbaras, we need to distinguish the composite sense (de dicto):

$$
\square(\forall x)(B x \rightarrow A x)
$$

from the divided sense (de re):

$$
(\forall x)(B x \rightarrow \square A x)
$$

of the major premise. Aristotle's argument is valid in the latter sense:

$$
(\forall x)(B x \rightarrow \square A x),(\forall x)(C x \rightarrow B x) \models(\forall x)(C x \rightarrow \square A x),
$$

but Theophrastus is right that it fails if he was taking the major premise de dicto:

$$
\square(\forall x)(B x \rightarrow A x),(\forall x)(C x \rightarrow B x) \not \models \square(\forall x)(C x \rightarrow A x),
$$

Whether or not this has any historical significance, it did increase our understanding of modality to distingush what Lakatos would call the "proof-generated concepts" of necessity de re and de dicto.

The other distinction which Ockham is employing in the passage above is that between a necessary proposition (a proposition which is necessarily true) and a proposition of necessity (a necessity-proposition: propositio de necessario). The former is what he means by an unrestricted assertoric (de inesse simpliciter). If the major premise of an XLL syllogism in the first figure is an unqualified assertoric, it is essentially a de dicto necessity, and so the syllogism reduces to LLL, which is always valid (if the corresponding assertoric syllogism is). ${ }^{27}$

To see the validity of all LLL syllogisms (as Aristotle shows in Prior Analytics I 8), we need to observe that necessity distributes over conjunction and entailment. Aristotle notes the latter at Prior Analytics I 15:

"So if one assigned $A$ to the premises, $B$ to the conclusion, the result would be, not only that if $A$ is necessary, $B$ is necessary at the same time, but also that if $A$ is possible, $B$ is possible." (34a22-24)

\footnotetext{
${ }^{26}$ Et si dicatur quod Philosophus negat unam et concedit aliam, igitur falsum est quod hic dicitur quod ita valet una sicut alia, dicendum est quod Philosophus loquitur de illa de necessario in sensu divisionis; et tunc patet evidenter quod maiore existente de necessario et minore de inesse sequitur conclusio de necessario, et hoc sive minor sit de inesse simpliciter sive de inesse ut nunc. Non sic autem valet talis discursus si maior sit de inesse, et ideo negat unam mixtionem et concedit aliam. (my translation) An alternative translation, and discussion, can be found at [Thom, 2003, p. 154].

${ }^{27}$ See Thom [2003, pp. 151-2].
} 
However, recognising that necessity (unlike possibility) also distributes over conjunction had to wait longer, since it was not until the twelfth century that a conjunctive proposition was even recognised as such. Martin [2012, pp. 295-8] notes that Boethius denies that conjunctive constructions produce single propositions (rather than a complex of propositions), and cites Abelard's recognition of the conjunctive proposition (propositio copulativa) as "a fundamental turning point in the history of logic". Abelard writes:

"Since 〈Boethius〉 concedes that 'if it's day, then it's light' is a single proposition in which different propositions are reduced to the sense of one proposition by the proposed conjunction [that is, 'if'], I do not see why 'both Apollo is a prophet and Jupiter thunders' cannot be said to be a single proposition, just like 'when Apollo is a prophet, Jupiter thunders'." 28

Once the premises are conceived as a single proposition, the necessity attaching separately to each premise now applies to the antecedent as a whole, and so transfers to the conclusion by the distribution of necessity over entailment. Speaking first of the composite sense of the premises, Buridan [2014, IV 1, pp. 141-2] writes:

"In every figure, nothing follows from composite [premises] of possibility or of contingency, but from composite [premises] both of necessity ... there follows a composite conclusion of the same sort ... Now every conjunction ... composed of necessities is necessary ... So if both premises are necessary, the whole antecedent is necessary, hence the conclusion is necessary."

Taking the premises in the divided sense is more tricky, but still yields a conclusion of necessity, at least a direct conclusion. ${ }^{29}$ More generally, if a consequence holds, it holds of necessity, as Aristotle said, that is, entailments and logical truths hold necessarily.

However, if we do use the notion of divided necessity (that is, de re) to explain Aristotle's reason for endorsing first-figure LXL syllogisms, we seem committed to attributing inconsistency to him. For in Prior Analytics I 3, and elsewhere, Aristotle endorses modal conversions such as that of Le and $\mathrm{Li}$, which hold only de dicto, not de re. ${ }^{30}$ Moreover, some of his proofs of modal syllogisms appeal to these conversion principles, e.g., that of Celarent LQX at 36a7-15. ${ }^{31}$ But it would be a mistake to infer from the stupendous achievement that Aristotle's logic represents that he was infallible, and try too hard to find an interpretation of the modal notions which makes every claim of Aristotle's correct. Indeed, many such interpretations, however successful, are historically implausible as truly Aristotle's own interpretation. ${ }^{32}$

\footnotetext{
${ }^{28}$ Jacobi and Strub [2010, p. 160]: "Cum enim concedat unam esse propositionem 'Si dies est, lux est', in qua diversae propositiones ad unum sensum reducuntur per coniunctionem praepositam, non video, quare una propositio dici non possit 'Et Apollo vates est et Jupiter tonat' sicut 'Quando vates est, Jupiter tonat'."

${ }^{29}$ Buridan [2014, IV 2 conclusions 4, 5 and 6, pp. 143-4]; Ockham [1974, III-1 20, pp. 412-3].

${ }^{30}$ Le-conversion takes us from 'No $B$ s are necessarily $A$ ' to 'No $A$ s are necessarily $B$ ', and Li-conversion from 'Some $B$ s are necessarily $A$ ' to 'Some $B$ s are necessarily $A$ '.

${ }^{31}$ See Henle [1949, p. 99]. Celarent LQX reads: No $B$ s are possibly $A$, all $C$ s are contingently $B$, so no $C$ s are $A$. Aristotle's proof appeals both to Le-conversion (from 'No $B$ s are possibly $A$ ' to 'No $A$ s are possibly $B$ ') and Celarent and Ferio LXL.

${ }^{32}$ Even Malink [2013, p. 270] admits, concerning his suggested interpretation of propositions of possibility and contingency, that it is "unlikely that Aristotle endorsed them and had them in mind when he developed the problematic syllogistic."
} 
In any case, what we should recognise from this cursory survey of the history of modal logic is its a posteriori nature. Aristotle's proof of the first-figure LXL syllogisms met Theophrastus' heuristic falsifier. Lakatos contrasted "logical falsifiers" with "heuristic falsifiers":

"If we accept the view that a formal axiomatic theory implicitly defines its subjectmatter, then there would be no mathematical falsifiers except the logical ones ["statements of the form $p \& \neg p "$-loc.cit.]. But if we insist that a formal theory should be a formalization of our informal theory, then a formal theory may be said to be 'refuted' if one of its theorems is negated by the corresponding theorem of the informal theory. One could call such an informal theorem a heuristic falsifier of the formal theory." [Lakatos, 1978b, p. 36]

Aristotle's formal theory of modality, the modal syllogistic, may well have logical falsifiers. ${ }^{33}$ But more interesting for the development of the subject were cases where the formal theory did not accord with the everyday or informal reasoning it attempted to codify. A proper logical theory, if not just a formal game, must come with bridge principles connecting it to our reasoning practices. The tension set up by the heuristic falsifiers led subsequent thinkers to draw distinctions which yielded to deeper understanding of the nature of modality.

But Lakatos went further. He presents, he says,

'a very different picture ... from Popper's. The best opening gambit is not a falsifiable ... hypothesis, but a research programme ... 'Crucial experiments' in Popper's sense do not exist: at best they are honorific titles conferred on certain anomalies long after the event." [Lakatos, 1978a, p. 150]

A research programme will evolve, responding to verifications as much as to refutations, relying on a "positive heuristic" built on "a preconceived underlying idea":

"It is primarily the positive heuristic of [the scientist's] programme, not the anomalies, which dictate the choice of his problems." [Lakatos, 1978a, p. 149]

\section{Analyticity}

We have seen that logic (and mathematics) are both necessary and, in a useful sense, a posteriori, and so, methodologically, unexceptional. Kripke showed that such empirical discoveries as that Hesperus is Phosphorus, and that water is $\mathrm{H}_{2} \mathrm{O}$, can be necessary (though he calls them "necessary a posteriori" - Kripke [1980, p. 38]). But are they analytic? [Kripke, 1980, pp. 39, 56n.] simply stipulates that none of them is "true by virtue of its meaning" - that is, metaphysically analytic. We noted in $\S 1$ that Williamson finds this notion unhelpful. The real question is whether any truths are epistemically analytic and a posteriori in the sense identified in $\S 2$.

I argued elsewhere [Read, 2015b, p. 137] that even Boghossian's characterisation of epistemic analyticity as yielding knowledge is mistaken, for not all analytic statements are in fact true. Adopting the wrong concepts can commit one to false claims - claims one is justified in believing in virtue of the concepts involved, but nonetheless false. Take the concept 'Tommy' (short for 'Tommy Atkins'): in my idiolect, at least, Tommies are always brave, "decent chaps". But at the same time, 'Tommy' is just a name for an ordinary British soldier (a private). It follows that any

\footnotetext{
${ }^{33}$ Thom [1996, §20.1, pp. 132-8] gives some examples.
} 
British private is a Tommy, and Tommies are always brave. So all British privates are brave (and decent). Sadly, that is not true. Hence it is an analytic falsehood - not that it is false in virtue of its meaning; quite the contrary: it is false despite the fact that I am committed by the meaning I attach to the term to assent to that falsehood. If I include it in my vocabulary, its very meaning entitles me, indeed, commits me to inferring that all British privates are brave. It justifies me in holding a false belief.

Dummett [1973, p. 454] describes the logical behavour of the related term 'Boche' in what would now be called inferentialist terms. Broadly, he says [1973, p. 396], the rules for an assertion are of two fundamental types. One type specifies the conditions under which the assertion is appropriate; the other specifies the consequences of that assertion. More specifically, inferentialism focusses on the rules for an expression, so that its introduction-rules specify the grounds for making assertions containing the expression, and the elimination-rules describe the consequences of making those assertions. The mismatch between grounds and consequences which affects terms like 'Boche' and Prior's notorious 'tonk' [Prior, 1960] led Dummett and others to demand a consonance (technically referred to as "harmony" and "stability"-Dummett [1991, pp. 215, 287]) between grounds and assertion. ${ }^{34}$ Thereby, the meaning of an expression would be captured inferentially by specifying the grounds, or introduction-rules, for the expression, so that those rules became self-justifying (or "autonomous") by being, as Gentzen [1969, p. 80] suggested, "definitions" of the terms involved. Provided the E-rules lie in harmony with the I-rules (or better, provided the I- and E-rules are stable), the E-rules express the same meaning as the I-rules, and so are themselves justified by that meaning. The problem with terms like 'Tommy', 'Boche', 'tonk' and the like is that the meanings captured by the two types of rule are different, and the rules are not harmonious or stable.

Williamson [2007, p. 76] criticizes inferentialism for tying meaning (or understanding) too closely to assent (or assertion). He complains that it sets up understanding-assent links which deny understanding to anyone who dissents from doctrines supposedly encapsulated in the meaning of the term. One example he gives [2007, p. 78] features phlogiston. Phlogiston was a substance postulated to explain combustion: combustible substances were those containing phlogiston, which was then released into the air when they caught fire. The theory turned out to be false, and was disproven when it was found that things that caught fire weighed more after burning than beforethe right explanation being that they had absorbed oxygen from the air. Nonetheless, belief in phlogiston, that is, in the theory which would justify one in asserting that a substance contained phlogiston if it was combustible (an example of Aristotelian a posteriori reasoning) made that inference analytic. That combustible substances contain phlogiston is, in that sense, analytic, a posteriori (in the medieval sense) and empirically false.

Williamson $[2007$, p. 78$]$ is puzzled that understanding phlogiston theory could lead to such false beliefs:

"If an understanding-assent link holds for 'phlogiston', and understanding 'phlogiston' necessitates assent to a core of phlogiston theory, how could it follow that someone understands sentences of phlogiston theory only if a core of it is true? Didn't exponents of phlogiston theory understand their own theory, despite its untruth?"

But that is why we have to be careful with words like 'phlogiston', 'Boche', 'tonk' and so on. We have to treat them metalinguistically, at arm's length. We can't adopt them into our vocabulary

\footnotetext{
${ }^{34}$ For clarification of the concepts of harmony and stability, see Jacinto and Read [2017, §4].
} 
without acquiring certain commitments. But we can know what the theory says without endorsing it.

Williamson considers this response, but still claims to find it problematic. In place of the understanding-assent, understanding-knowledge and understanding-truth links, he suggests the inferentialist might retreat to proposing an understanding-justification link:

"Necessarily, whoever understands the sentence ... is justified in asserting it." [Williamson, 2007, p. 80]

He claims that "this retreat from knowledge and truth to justification does less than full justice to the example." But his argument appears to turn on an equivocation over the notion of justification. Although the notion of justification is, he says, "conceived as non-factive", he claims that a "last-ditch defender of phlogiston theory ... [can] continue to accept it long after the accumulating negative evidence has made this unjustifiable." But that is to take justification as dependent on the evidence. That may make it unreasonable, but either Williamson must admit that countervailing considerations can make someone both justified (in the light of certain considerations) and unjustified (in light of others); or if the evidence really can undercut other considerations (namely, commitment to the theory) then he is taking justification factively, as yielding knowledge and so as entailing truth. ${ }^{35}$ But in [Williamson, 2013b, p. 424], he concedes that "entail' here means by the standards of the theory in question rather than by common standards."

To press home his case, Williamson invites us to consider the case of Peter, as he dubs him, who thinks (misguidedly, Williamson claims) that universal affirmatives not only presuppose the non-emptiness of their subject, but actually entail it. (Perhaps Williamson is aware that many philosophers have held this view, but if so, he gives no inkling of it. I argued in Read [2015a] that this was the commonly-held view of Aristotle, Avicenna, Ockham and Buridan, among others.) Moreover, for his own strange reasons, Peter thinks there are no vixens. So he denies the truth of 'Every vixen is a vixen'. But the understanding-assent link for 'vixen' requires, Williamson says, that 'Every vixen is a vixen' is analytic, and so must be assented to by anyone who understands 'vixen'. Hence, Williamson infers, the inferentialist is committed to denying that Peter misunderstands the term 'vixen'.

Of course, if Aristotle and his successors were right to accord existential import to universal affirmatives, then understanding ' $F$ ' would not commit one to endorsing 'Every $F$ is an $F$ '. We have an example of meaning-belief holism, an instance of the Duhem-Quine indeterminacy thesis that led to Lakatos' initial distancing from Popper's simple falsificationism. But even if Williamson is right in his denial of existential import and his commitment to the prevailing orthodoxy that universal affirmatives are quantified material conditionals, Peter's refusal to assent to 'Every vixen is a vixen' does not show that he doesn't understand 'vixen', but that he misunderstands 'every'. Williamson's mistaken attachment to the truth-functional account of conditionals and of universal affirmatives as quantified material conditionals leads him, like his protagonist Peter, to endorsing false analytic claims, even setting aside the question of existential commitment. Take Newton's first law of motion, for example:

Any object not acted on by an external force continues at rest or in uniform motion in a straight line.

There are no objects not acted on by an external force, so Williamson must believe this to be vacuously true. The same for:

\footnotetext{
${ }^{35}$ In Williamson [2000, ch. 9] he identified knowledge with evidence.
} 
Any object not acted on by an external force dances a tango in a figure of eight.

But $(*)$ is false, and Newton's first law is not vacuously true, but constituted a huge step forward in explaining the motion of physical objects. It is not a trivial consequence of the fact that every object is subject to external forces from the rest of the universe. Rather, with the other laws, it was the best explanation of Kepler's Laws, inferred a posteriori by abduction from observation.

\section{Conservatism}

Williamson does not deny that logic and mathematics can be prosecuted from the armchair. They do differ in important ways from natural science and other empirical investigations. His antiexceptionalist claim is that their methodology is not different. Where Williamson errs is to claim that the abductive methodology in logic favours the status quo. He claims [2017, p. 30] that he is not urging a conservatism, that he is not simply relying on the established position of classical logic to defend it. But consider his argument in favour of classical logic, that greater strength favours a theory by giving it greater informativeness [2017, pp. 17-18]. Classical logic is as informative as it gets, he says (p. 19), because it is Post-complete (at least in its propositional fragment), that is, it cannot be extended (or could not say more) without collapsing into contradiction and triviality. But classical logic is not the only Post-complete propositional logic. Abelian logic is also Post-complete. ${ }^{36}$ Why favour one Post-complete logic over the other? A good argument would still ask which logic was the right one: information is not everything, if some of that information is wrong. In the case of Abelian logic, some is indeed wrong: e.g.,

$$
((p \rightarrow q) \rightarrow q) \rightarrow p
$$

is valid in Abelian logic, but is simply false (as an account of conditionals). It meets a heuristic falsifier, taking the falsehood 'Paris is in Italy' for ' $p$ ' and the truth 'If Paris is in Italy then Paris is in Europe' for ' $q$ '. Then the antecedent of $(* *)$ is an instance of contraction:

If Paris is in Italy only if Paris is in Italy only if Paris is in Europe, then Paris is in Italy only if Paris is in Europe,

and so is true, but the consequent of $(* *)$ is false. Thus Abelian logic, despite being, in terms of strength alone, maximally informative, is not really informative since some of the "information" it imparts is false. Thus Williamson's argument in favour of classical logic fails. Classical logic, despite also being maximally informative in terms of strength, might similarly be not really informative if some of that "information" is not true. We saw that this is indeed the case with the example of Newton's first law, for unconstrained use of classical logic in evaluating alternatives to the law would lead to endorsing falsehoods - it too meets heuristic falsifiers. ${ }^{37}$

This shows that Williamson's second argument in [2017, pp. 22-23] in favour of classical logic, namely, its heavy involvement in science, is also, despite his protestations, a case of conservatism, a defence of the status quo. Whether full classical logic is so closely tied to scientific theory is

\footnotetext{
${ }^{36}$ See Meyer and Slaney [1989], especially p. 275, where they anticipate Williamson's argument from strength, and comment: "this evidently unsound reasoning ... can clearly be seen to be based on a hopeless confusion."

${ }^{37}$ Hjortland [2017, §4.2] gives further reasons to resist Williamson's argument from strength, on the grounds that weaker logics have greater expressive power.
} 
questionable, but if so, that should worry us, since as we see, some of its consequences are false: Newton's first law is not trivially true, and its contraries, like $\left(^{*}\right)$, are false.

What transpires to be the a posteriori nature of logic (and mathematics and philosophy) does not show that it is neither analytic nor necessary. It is both. That does not make it infallible, however. Endorsing the theories embodied in certain expressions, like 'phlogiston', for example, may commit one to consequential assertions simply in virtue of the meaning of these expressions, but those consequences can be mistaken and the assertions, though analytic of the expressions, may be false. Williamson tried to refute inferentialism, with its claim that the meaning of certain expressions was given by the rules for their use, by questioning the understanding-assent links that seem to be involved. But certain expressions come with the heavy baggage of mistaken theories (in the case of 'phlogiston') or prejudices (in the case of 'Tommy' and 'Boche') or logics (in the case of 'tonk'), and commitment to these false beliefs can be avoided only by refraining from using those expressions in propria persona. One can understand such expressions, that is, know what they mean, without endorsing them and so refusing to incorporate them into one's own vocabulary.

This is as true of logic as of scientific theories or racial prejudices. A logic is not just a formal theory: any logic worth the name comes, like any decent scientific theory, with bridging principles which connect it with practice - in the case of logic, with our reasoning practices. So not only can there be logical falsifiers of a logic (e.g, the fact that adding 'tonk' to any transitive logic results in triviality), as of any theory, but also heuristic falsifiers, implications for our reasoning practices which may show their untenability a posteriori. Logical consequence holds in virtue of the meaning of the logical terms. In that respect, logic is exceptional. But its methodology and its epistemology are the same as those of science in being fallibilist, and counterexamples to seemingly analytic truths are as likely as those in any scientific endeavour.

But not all heuristic falsifiers should be accepted. Consider, for example, Vann McGee's proposed counterexample to modus ponens. ${ }^{38}$ Here an anomaly comes up against part of the positive heuristic. Central to the aim of logic is logical consequence, and consequence is standardly expressed by conditionals. Modus ponens is analytic of 'if' as a logical connective. ${ }^{39}$ As Williamson shows, the dominant response has been to deflect McGee's example using the resources of logical theory. To the extent that they are successful, they add support to the theory. Those who reject disjunctive syllogism in the form of MP for material implication, for example, see it as bearing out their claim that 'if not- $A$ then $B$ ' is not entailed by $A$. McGee's purportedly invalid argument has the form: 'if $C$ then if not- $A$ then $B, C$, so if not- $A$ then $B$ ', where there is strong reason to beiieve 'if $C$ then $A$ '. It's that further information that undermines the inference and encourages denial of the conclusion. Given $C$ and the strong reason to believe 'if $C$ then $A$ ', it follows that $A$, so for Gricean reasons it would be misleading to infer the weaker conclusion 'if not- $A$ then $B$ '. ${ }^{40}$ Anomalies can have beneficial, as well as disruptive, effects. What counts is what provides the best explanation.

Just as scientific theories are evaluated in light of how well they fit the evidence, so too are logical theories, regarding their success in taking us by suitable reasoning processes from premises to conclusion. Like Lakatos, Williamson [2017, p. 18] cites Russell with approval for advocating the abductive method in mathematical philosophy, including logic, this time from Russell [1919, p. 2], written around the same time as Russell [1956]:

\footnotetext{
${ }^{38}$ See McGee [1985] and Williamson [2007, p. 92].

${ }^{39}$ See Read [1994, §4].

${ }^{40}$ See Grice [1975].
} 
"We need two sorts of instruments for the enlargement of our logical powers, one to take us forward to the higher mathematics, the other to take us backward to the logical foundations of the things we are inclined to take for granted in mathematics."

These are Aristotle's contrasting methods of demonstration, of the fact entailed by the reason or cause (which the medievals termed demonstration propter quid - why, or a priori), and from the fact to the reason why (demonstration quia, or a posteriori). The meaning of those terms was changed by Kant, ostensibly by restricting the scope of the a priori to the non-empirical, but also by excluding the a posteriori from the armchair. Thus the a posteriori became identified with the empirical, at the very least suggesting a difference in methodology, which classed logic, mathematics and philosophy as somehow exceptions to the general picture. Williamson was right to challenge this conception.

Williamson [2013c] rejects the a priori/a posteriori distinction as unhelpful in its unclarity over the role of experience in judgement, and seeks a new distinction properly to reflect the methodology underlying our search for knowledge. That distinction was there all along in Aristotle's preKantian account of demonstration, which the medievals captured in the language of 'a priori' and 'a posteriori': we add to our knowledge by reasoning a posteriori, and we apply that knowledge when we reason a priori.

\section{References}

Albert the Great. De Demonstratione, id est, Posteriorum Analyticorum libri 2. In Pierre Jammy, editor, Beati Alberti Magni Opera Quae Hactenus Haberi Potuerunt, volume 1, pages 513-658. Claude Prost et al., Lyons, 1651.

Alexander of Aphrodisias. On Aristotle Prior Analytics 1.8-13. Duckworth, London, 1999. Translated by Ian Mueller with Josiah Gould. Introduction, Notes and Appendices by Ian Mueller.

Aristotle. Posterior Analytics. Clarendon Aristotle Series. Clarendon Press, Oxford, 1975. Translated with Notes by Jonathan Barnes.

Aristotle. Prior Analytics Book I. Clarendon Aristotle Series. Clarendon Press, Oxford, 2009. Translated with an Introduction and Commentary by Gisela Striker.

Roger Bacon. The Art and Science of Logic. Pontifical Institute of Mediaeval Studies, Toronto, 2009. Translated by Thomas Maloney.

Ruth Barcan Marcus. Modalities and intensional languages. Synthese, 13:303-22, 1961.

Albrecht Becker. Die Aristotelische Theorie der Möglichkeitsschlüsse: eine logisch-philologische Untersuchung der Kapitel 13-22 von Aristoteles Analytica Priora I. Junker \& Dünnhaupt, Berlin, 1933.

Paul Boghossian. Analyticity. In B. Hale and C. Wright, editors, A Companion to the Philosophy of Language, pages 331-68. Blackwell, Oxford, 1997.

J. Buridan. Tractatus de Consequentiis. Fordham UP, New York, 2014. English translation by Stephen Read. 
John Buridan. Questions on the Posterior Analytics. H. Hubien ed., n.d. URL http://individual. utoronto.ca/pking/resources/buridan/QQ_in_Post_An.txt.

J. Corcoran. Aristotle's natural deduction system. In J. Corcoran, editor, Ancient Logic and its Modern Interpretations, pages 85-131. Reidel, Dordrecht, 1974.

Igor Douven. Abduction. In Edward N. Zalta, editor, The Stanford Encyclopedia of Philosophy. Spring 2011 edition, 2011.

Michael Dummett. Frege: Philosophy of Language. Duckworth, London, 1973.

Michael Dummett. Frege's distinction between sense and reference. In Truth and other Enigmas Dummett [1978b], pages 116-44.

Michael Dummett. Truth and other Enigmas. Duckworth, London, 1978b.

Michael Dummett. Logical Basis of Metaphysics. Duckworth, London, 1991.

Gerhard Gentzen. Investigations concerning logical deduction. In The Collected Papers of Gerhard Gentzen, pages 68-131. North-Holland, Amsterdam, 1969. Edited by M. Szabo.

H. Paul Grice. Logic and conversation. Syntax and Semantics, 3:41-58, 1975.

Paul Henle. On the fourth figure of the syllogism. Philosophy of Science, 16:94-104, 1949.

Ole Hjortland. Anti-exceptionalism about logic. Philosophical Studies, 174:631-58, 2017.

Peter Hylton. Willard van Orman Quine. In Edward N. Zalta, editor, The Stanford Encyclopedia of Philosophy. Winter 2014 edition, 2014.

Bruno Jacinto and Stephen Read. General-elimination stability. Studia Logica, 105:361-405, 2017.

Klaus Jacobi and Christian. Strub, editors. Petri Alaelardi Glossae super Peri Hermeneias. Brepols, Turnhout, 2010.

Immanuel Kant. Critique of Pure Reason. Macmillan., London, 1963. Translated by Norman Kemp Smith.

Saul Kripke. A puzzle about belief. In A. Margalit, editor, Meaning and Use, pages 239-83. Reidel, 1979.

Saul Kripke. Naming and Necessity. Blackwell, Oxford, 1980.

Saul Kripke. Philosophical Troubles. Oxford University Press, Oxford, 2011.

Imre Lakatos. Proofs and Refutations. Cambridge UP, Cambridge, 1976. Edited by John Worrall and Gregory Currie.

Imre Lakatos. Popper on demarcation and induction. In John Worrall and Gregory Currie, editors, The Methodology of Scientific Research Programmes, pages 139-67. Cambridge UP, Cambridge, 1978a.

Australasian Journal of Logic (16:7) 2019, Article no. 6 
Imre Lakatos. A renaissance of empiricism in the recent philosophy of mathematics. In John Worrall and Gregory Currie, editors, Mathematics, Science and Epistemology, pages 24-42. Cambridge UP, Cambridge, 1978b.

John Longeway. Medieval theories of demonstration. In Edward N. Zalta, editor, The Stanford Encyclopedia of Philosophy. Spring 2009 edition, 2009.

John Mackie. Causes and conditions. American Philosophical Quarterly, 12:245-65, 1965.

Marko Malink. Aristotle's Modal Syllogistic. Harvard U.P., Cambridge, Mass., 2013.

Chris Martin. Logical consequence. In John Marenbon, editor, The Oxford Handbook of Medieval Philosophy, pages 289-311. Oxford UP, Oxford, 2012.

Vann McGee. A counterexample to modus ponens. The Journal of Philosophy, 82:462-71, 1985.

Robert K. Meyer and John Slaney. Abelian logic. In Graham Priest, Richard Routley, and J. Norman, editors, Paraconsistent logic: Essays on the Inconsistent, pages 245-88. Philosophica Verlag, Munich, 1989.

Alan Musgrave and Charles Pigden. Imre Lakatos. In Edward N. Zalta, editor, The Stanford Encyclopedia of Philosophy. Summer 2016 edition, 2016.

Gulielmus de Ockham. Summa Logicae. Franciscan Institute Publications, St Bonaventure, 1974. Edited by P. Boehner et al.

Gulielmus de Ockham. Demonstration and Scientific Knowledge in William of Ockham. University of Notre Dame, Notre Dame, 2007. English translation by John Lee Longeway.

Graham Priest. Unstable solutions to the liar paradox. In S.J. Bartlett and P. Suber, editors, Self Reference: Reflections and Reflexivity, pages 145-175. Nijhoff, Dordrecht, 1987.

Graham Priest. In Contradiction. Clarendon Press, Oxford, 2 edition, 2006.

Arthur N. Prior. The runabout inference ticket. Analysis, 21:38-39, 1960.

Willard V. Quine. Word and Object. The MIT Press, Cambridge, Mass., 1960.

Willard V. Quine. Two dogmas of empiricism. In From a Logical Point of View, pages 20-46. Harper \& Row, New York, 1961a.

Willard V. Quine. Reply to Professor Marcus. Synthese, 13:323-30, 1961b.

Willard V. Quine. Three grades of modal involvement. In Ways of Paradox, pages 156-74. Random House, New York, 1966.

Willard V. Quine. Philosophy of Logic. Prentice-Hall, Englewood Cliffs, 1970.

S. Read. Formal and material consequence. Journal of Philosophical Logic, 23:247-65, 1994.

Stephen Read. The objective being of Ockham's ficta. The Philosophical Quarterly, 27:14-31, 1977.

Australasian Journal of Logic (16:7) 2019, Article no. 6 
Stephen Read. Aristotle and Łukasiewicz on existential import. Journal of the American Philosophical Association, 1:535-44, 2015a.

Stephen Read. Proof-theoretic validity. In C. Caret and O. Hjortland, editors, Foundations of Logical Consequence, pages 136-58. Oxford University Press, 2015b.

B. Russell. The regressive method of discovering the premises of mathematics. In D. Lackey, editor, Essays in Analysis, pages 272-83. George Allen \& Unwin, London, 1973.

Bertrand Russell. Introduction to Mathematical Philosophy. George Allen \& Unwin, London, 1919.

Bertrand Russell. Logical atomism. In Robert Marsh, editor, Logic and Knowledge, pages 323-43. George Allen \& Unwin, London, 1956.

Wilfrid Sellars. The Metaphysics of Epistemology. Ridgeview Publishing Co., Atascadero, Calif., 1989.

Aaron Sloman. 'Necessary', 'a priori' and 'analytic'. Analysis, 26:12-16, 1965-66.

Theophrastus of Ephesus. Sources for his Life, Writings, Thought and Influence. Brill, Leiden, 1992. Edited and translated by William W. Fortenbaugh, Pamela H. Huby, Robert W. Sharples (Greek and Latin) and Dimitri Gutas (Arabic).

Paul Thom. The Logic of Essentialism: an Interpretation of Aristotle's Modal Syllogistic. Kluwer, Dordrecht, 1996.

Paul Thom. Medieval Modal Systems. Ashgate, Farnham, 2003.

Tim Williamson. Knowledge and its Limits. Oxford UP, Oxford, 2000.

Tim Williamson. The Philosophy of Philosophy. Blackwells, Oxford, 2007.

Tim Williamson. Anti-exceptionalism about philosophy. Croatian Journal of Philosophy, 37:1-3, 2013a.

Tim Williamson. Modal Logic as Metaphysics. Oxford UP, Oxford, 2013b.

Tim Williamson. Abductive philosophy. The Philosophical Forum, 47:263-80, 2016.

Tim Williamson. Semantic paradoxes and abductive methodology. In Brad Armour-Garb, editor, Reflections on the Liar, pages 325-46. Oxford UP, Oxford, 2017.

Timothy Williamson. How deep is the distinction between a priori and a posteriori knowledge? In Albert Casullo and Joshua C. Thurow, editors, The A Priori in Philosophy, pages 291-312. Oxford University Press, 2013c. 